\title{
A (computational) social science perspective on societal transitions
}

\author{
Flaminio Squazzoni
}

Published online: 30 September 2008

(C) Springer Science+Business Media, LLC 2008

\begin{abstract}
This paper aims to illustrate how social sciences, sociology in particular, have theorized on societal transitions. The first section introduces some preliminary definitions. The assumption is that a societal transition is more than a social, economic or technological change. It is a large-scale and long-term macro process through which a given social system radically changes its structural basis, in terms of new socio-technical practices, governance rules, social and economic institutions, cultural frames, and patterns of social life. The second section provides an excursus on social science accounts on transitions. In particular, the attention has been given to Norbert Elias' famous study on the rise and fall of the court society in France, between 17th and 18th century and to Manuel Castells' recent analysis of the emergence of the network society. The third section discusses problems and challenges of standard approaches and suggests some building blocks of societal transition models, taken from complexity and social simulation literature. The concluding section suggests some way-forward measures towards a computational social science approach to societal transitions.
\end{abstract}

Keywords Societal transitions $\cdot$ Agent-based models $\cdot$ Social simulation $\cdot$ Norbert Elias · Manuel Castells

\section{Introduction}

The relevance of societal transitions has significantly increased in the recent years, with the common recognition of climate change, the demographic challenges, and the need for sustainable development. This has encouraged the scientific community to

\footnotetext{
F. Squazzoni ( $₫)$

Department of Social Sciences, University of Brescia, Via S. Faustino, 74/B, 25122 Brescia, Italy

e-mail: squazzon@eco.unibs.it

url: http://www.unibs.it/on-line/dss/Home/Personale/PersonaleDocente/articolo1758.html
} 
give more attention to the analytical mechanisms behind societal transitions, as well as to management and policy making issues (e.g., Aassve et al. 2006; Fisher-Kowalski and Haberl 2007; Raskin et al. 2002; Van den Berg and Bruinsma 2008).

This paper aims to illustrate how social sciences, sociology in particular, have theorized on societal transitions, with the purpose to introduce a social science perspective to the present debate, which is mostly concerned with complexity, socioenvironmental patterns, management and policy making implications. Section 2 introduces some preliminary definitions. It is argued that a societal transition may be understood as a large-scale and long-term macro process through which a given social system radically changes its structural basis, in terms of new socio-technical practices, governance rules, institutions, cultural frames, and patterns of social life. Section 3 provides some examples (due to shortage of space, not exhaustively) on how social scientists, particularly sociologists, have dealt with these issues. In this regard, two classical studies are presented: Norbert Elias' famous essay on the rise and fall of the court society in France, between 17th and 18th century (Elias 1969), and Manuel Castells' analysis of the rise of the network society ${ }^{1}$ (Castells 2000a, 2000 b, 2004a). These studies are good examples of a social science approach to societal transitions, as well as to its pros and cons. Section 4 summarizes problems and challenges in building theoretical models of societal transitions. It is argued that the main challenge of transition studies is to work with analytical models that allow us to map the micro-macro generative mechanisms that can explain the emergence of transitions, at the same time making traceable the alignment of intersectoral changes that characterizes each societal transition. Some intuitions in such a direction will come from the literature on complexity and social simulation. Finally, Sect. 5 elaborates on some way-forward measures towards a computational social science approach to transitions. The aim is to suggest some humble guidelines toward an analytical approach to societal transitions that should be, on one hand, strongly attached to social science evidence, background and experience, and, on the other hand, capable of genuinely benefiting from formal modeling and computational techniques.

\section{Preliminary definitions}

In the recent literature, there are many possible definitions of what a societal transition is:

"a non-linear process of social change in which the structure of a societal system (energy sector, water management, agriculture, mobility) transforms" (Rotmans et al. 2001);

"outcomes of alignments between developments at multiple levels [...] changes from one socio-technical regimes to another" (Geels and Schot 2007);

\footnotetext{
${ }^{1}$ Right from the beginning, it is worth clarifying that each example reported in this paper is an idealtypical analysis of societal transition. This paper does not aim to offer a critical evaluation on the specific arguments suggested by the quoted authors. No critical literature on, let us say, Elias' arguments on the causes of the French revolution, or on Castells' theory of identity and nationalism will be reported. The purpose here is just to give some examples on how social scientists, especially sociologists, have dealt with societal transitions.
} 
"a long-term, continuous process of change during which a society or a subsystem of society fundamentally change", that is "a set of interconnected changes which reinforce each other but take place in different areas, such as technology, the economy, institutions, ecology, culture, behavior and belief systems" (Rotmans and Kemp 2003);

"transitions are complex junctures in which the entire cultural matrix and the relationship of humanity to nature are transformed" (Raskin et al. 2002);

"a transition comprises a society-wide change that goes beyond single sectors and involves fundamental and interrelated changes in technology, organization, institutions and culture" (Van den Berg and Kemp 2008).

For the sake of our purpose, ${ }^{2}$ a societal transition may be understood as a largescale and long-term macro process through which a given social system comes to radically change its structural basis, in terms of new socio-technical practices, governance rules, social and economic institutions, cultural frames, and patterns of social life. The basic assumption is that a societal transition does not simply mean a "social", or an "economic", or a "technological" change, like the emergence of new lifestyles or the advent of a new socio-technical system. A societal transition means an alignment of changes occurring in different sectors of the society that should be traced at different levels of analysis (i.e., at the level of cultural frames of individuals, but also at the level of social institutions). This is the typical "complexity" of transitions that requires the analysis of a set of underlying complex processes, moving at the edge of chaos and order, at different time scales, according to far from equilibrium dynamics and path dependence (Byrne 1998).

From a descriptive viewpoint, it is expected that a transitions can go across a set of typological phases (e.g., see Martens and Rotmans 2005 on "take off", "acceleration", and "stabilization"), with some ideal-typical stages that can be generalized across the singular cases. The identification and description of phases, stages, tipping points, bifurcations, strange attractors, far from equilibrium dynamics are just a few examples of the theoretical toolkit increasingly used to grasp and describe the morphological patterns of transitions (e.g., Geels 2002; Geels and Schot 2007). But, to achieve an analytical understanding of societal transitions, it is necessarily required that researchers specify those micro-macro mechanisms which are responsible for the generation of the observed or expected macro transition patterns and that make traceable the alignment of the underlying intersectoral changes by means of formalized, abstracted and rigorous models (Hedström and Swedberg 1998; Hedström 2005). As it is argued in the last section of this paper, on this last aspect of the scientific inquiry, the societal transition field of research needs further progress.

\footnotetext{
${ }^{2}$ The analysis of the managerial implications of a transition theory is beyond the purpose of this paper, so also policy making issues. The purpose here is simply to clarify the analytical background of the recent studies on societal transitions, and to investigate related problems and challenges from a social science perspective.
} 


\section{Examples in standard social science}

As it is pointed out in the introductory essay of this special issue, although the roots of the concept of societal transition used in the recent literature may be found in complexity and socio-environmental sciences, social sciences, in particular history, economics and sociology, cover a good number of analyses of long-term societal transitions. Good examples can be found in the political science literature on modernization (e.g., Black 1966; Eisenstadt 1973), or in the historical and sociological literature on the emergence of capitalism (e.g., Wallerstein 1974; Braudel 1979; Rosenberg and Birdzell 1987).

To understand transitions, social scientists have used three types of theoretical constructs: dichotomies, synchronic theories, and historical diachronic models.

Dichotomies are extrapolations of "polar types of social systems" (Cox 1974). The purpose is, for instance, to explain the difference between modern and pre-modern societies by abstracting and comparing the differences in their respective constituencies. In this case, a societal transition may be viewed as the process through which a given society adheres to one of the "polar types". For instance, Ferdinand Tonnies (1887) launched the famous dichotomy of Gemeinschaft (community) and Gesellschaft (society), in which the former is at the core of a social system characterized by dense communal relationships, intimacy, common memories, languages, habits, shared experience, and the latter contributes to shape a social system on association, sectoral and contract-based relationships, and competition. Henry Maine stressed the relevance of the dichotomy between status and contract, the latter being a social system based on laws derived on the basis of the social positions acquired by individuals, regardless of their willingness, and the former being a social system based on laws derived by the mutual agreement and reciprocal obligations negotiated among individuals (Feaver 1969). Finally, Ėmile Durkheim (1893), one of the founding fathers of sociology, set the mechanical solidarity, which is typical of pre-modern societies, in which individuals are subordinated to family, family to clan, clan to tribes and so on, under the imperatives of sameness, against organic solidarity-based societies, which are the typical forms of modern societies, where solidarity depends on division of labor and the imperatives of difference. The weakness of this theoretical construct is that such a comparative exercise can not help identify and understand processes of social changes that bring about the transitions in question.

Synchronic theories aim at illustrating the general functioning and composition of societies as social systems. The most influential example is the famous Parsons model of traditional/modern societies, transitioning through differentiation and integration of social sub-systems (Parsons 1966, 1971). In this case, the societal transition toward modernization consists of a long-term generalized process of differentiation, specialization and mutual influence and adjustment among different sub-systems of a given social system, under the evolutionary law of the growth of complexity.

In the well known AGIL scheme, Parsons identified four functional sub-systems in every social system (i.e., Adaptation, Goal attainment, Integration, and Latency), five patterns of modernization variables (i.e., ascription vs. achievement, diffuseness vs. specificity, particularism vs. universalism, affectivity vs. instrumentalism, and collective orientation vs. self interest) (Parsons and Shils 1951), and four transition mechanisms that, in his view, could explain the transition of the social systems toward 
modernity: structural differentiation, which is the specialization and differentiation between the sub-systems mentioned above, adaptation, which is the availability of resources released by the old social structures, originally submitted to traditional constraints; integration, that is the inclusion of new structures, roles, values, norms; and values' generalization, which is the formulation of universalistic normative standards that allows the effective integration of new structures.

The weakness of this second theoretical construct lies in its functionalism, universalism and in its unique attention to the systemic coherence and the end state. Many critics of Parsons' theory have correctly emphasized that the unique attention to synchronism among given systemic variables implies the impossibility of understanding diachronic change. Moreover, the implicit adoption of a macro deterministic model based on the normative primacy of social structures largely underestimates the relevance of individual action and the emergent nature of social patterns (e.g., Boudon 1992, 1999; Castellani and Quitterer 2007).

Historical diachronic models focus on the analysis of processes of change over time, sometimes with the identification of ideal-typic stages and dynamics. These models allow us to focus on processes of societal changes and specify the hidden mechanisms behind their emergence. Two famous and brilliant examples of societal transition analyses that follow such an inspiration are Norbert Elias' essay on the court society and Manuel Castells' analysis of the network society. Although they are focused on very different transitions, and the authors belong to different eras of sociology (Elias may be viewed as the last classical sociologist, while Castells is a contemporary), such studies can be taken as exemplary reconstruction of a transition, with a sociological approach. As we will see, the weakness of this approach is that starting with empirical details and specificities of historical transitions it is difficult to achieve theoretical generalizations.

\subsection{A classic example: Norbert Elias' court society}

Elias' "Court Society", written in 1933 and then re-adjusted and published in 1969, covers the societal transition of the Ancien Régime in France from the feudal agrarianism to industrial urbanization, with a particular focus on the period between Louis XIV in the 17th century and Louis XVI in the 18th century, up to the French revolution (Elias 1969). Elias' aim was to extend the understanding of the development of Western societies by identifying the aristocracy and the courts, which emerged and developed from the Middle Ages, as ideal-typical forms of social organization, based on conspicuous consumption and social prestige-oriented horizontal and hierarchical power competition among social groups, which radically transformed social life of Western societies, constituting a concrete opposite to bourgeois morality and its forms of life.

As Van Krieken (1998) has correctly argued, behavior which the Protestant bourgeoisie would regard as irrational, "was exactly what was demanded by court society of all its members in order to function within its relations of power. In court society, individual existence and identity were profoundly representational-they consisted of how one exhibited one's position and status to everyone else, and this process of exhibition and performance was highly competitive and constantly fluctuating", like 
the share prices in the Stock exchange. But, at the same time, the court society phase increasingly materialized the same form of "rationality", based on the balance struck between short-term desires and long-term consequences of human action, which still characterizes the civilized man (Elias 1939).

The emergence of political centralization and courtization has been the result of various intertwines among different changes (Loyal and Quilley 2004). First, the long-term growth in the urban money economy, which facilitated, at the same time also being dependent upon, the power and increasing nuances of hostilities related to the centralization of the State, with the formation of rationalized administrative apparatuses in towns. Through the gained access to economic circuits, the centralized State gained access to greater military resources against the nobility, with the lower levels of the landed warlord nobility remaining confined to the control of depreciating provincial land assets. Step by step, the nobility transformed from an independent warrior class into a court aristocracy, with the growth and the centralization of the court society in Versailles. This transformation implied the prohibition of the recourse to violence as a means of settling dispute and the emergence of new socially shared behavioral codes. The increase of the internalized behavioral constraints upon individual action followed the rise of a representational way of social life that was typical of the court institutions.

The ultimate goal of the courtiers was not money accumulation, but the maximization of social prestige. The need for social prestige accumulation meant a deep transformation of the social habitus and the personality structure of the courtiers. The personal detachment and the control over the passions were closely related to the growth of the social involvement in social interdependence settings like the court. The cult of the sociability, the removal of many bodily functions, the increase of repugnance's threshold, the diffusion of social stigmatization, the strategic behavior in the social prestige market of the court, the expressed rationality over face-to-face interaction, and the cognitive calculus of the long-term consequences of decisions and behavior, even vis-à-vis to apparently negligible situations, are all just components of a transition toward a new structure of the personality of the modern man. As a matter of fact, most of the component of such a transition became internalized by the middle classes as well (Loyal 2004).

But, the court mechanism, based on the interdependence between the king and its aristocracy, the court rituals and the conspicuous consumptions, generated an unintended and unplanned consequence. In fact, the political pacification following the rise of the court favored trade and economic growth that underwrote the economic and political power of the central authority, both of the king and the courtiers. Once the core of the political power and sociability, the court suddenly created a sort of an iron cage, in which the monopolistic elites, not only the king and the nobility, but also the highest bourgeoisie strata involved in the state administration, kept themselves in check, without being able to respond to the change of need levels and interests of the whole society. The court continued to be the kingdom of the social rank, which, however, gradually got divorced by effective power mechanisms, at last. The court shaped itself as an unintended and partially unplanned constriction mechanism both for the aristocracy, increasingly uprooted from its war and agrarian origins, and the King, who became vulnerable to this same mechanism of "strategification" of relationships 
(Szakolczai 2000). This eventuality favored the accumulation of economic power of the outside strata, as well as enhanced their political ambitions, thereby sowing the seeds for the French revolution.

The footprints of the transition toward the court society can be seen at very different levels of the changing nature of society of yore:

a) the changing structures and meanings of developments at the household level, which got reconfigured as a function of sociability and social duties, as a means to publicize the private life and the family, so as to demonstrate the prestige and to accumulate symbolic capital in others' eyes;

b) the ceremony of the King's lever, in which a meticulously ordered sequence of morning entrées projected a tangible image of how functions and people were endowed with prestige-values, how the people competed for them, and how, at the same time, the power of the King was dependent upon the social recognition of his authority and, therefore, upon his aristocracy;

c) the personal escape of courtiers towards the aristocratic romanticism, as a kind of re-appropriation of affective life against all the self-constraints that were imposed by the relevance of the public life; the court transition was reflected in a socially shared pattern of anxiety, ambivalence, and decadence, which exalted the artistic sentiments.

Louis XIV, while exploiting the intra-conflicts inside the nobility, became the sole reference for the nobility itself in order to resist to the pressure of the bourgeoisie strata, and their growing wealth, and also the reference for the bourgeoisie to protect against the threats and the old privileges of a still quasi-knightly nobility. The rise and the fall of the court society were not the result of a linear transition toward capitalism, or, let us say, of a transition from patrimonialism to bureaucracy, or again the result of the formation of a new social class that undertook new interests, new visions and ideas; but the transition was dependent upon a dynamic tension among social actors, groups and positions within a network of social interdependence that crystallized in the historical formation of the court.

Elias' analysis of the court society is used also today as a general model for studying both early modern courts and ancient monarchies (e.g. Spawforth 2007). Notwithstanding, the particular historical configuration of French absolute monarchy emphasized in Elias (1969) should be viewed just as one of the many 'solutions' given to the historical transition from agrarian feudalism to the era of national states in Europe (Rosenberg and Birdzell 1987). The French solution was followed, for example, by Spain and most of Eastern Europe (i.e., Prussia, Austria, and Poland), although with significant differences, but not in the case of Italy, for example (Anderson 1974). Moreover, it is worth emphasizing that Elias' court society should not be viewed as a prehistory of bourgeoisie society. It also reveals the emergence of a layer of social relations that characterizes the social evolution that followed, up to the present day. The relevance of social prestige, representation, symbolic capital and social differentiation for power relations is also prevalent today (Van Krieken 1998, 92). Elias himself has pointed it out as follows:

"there are in many organizations of our time, even industrial and commercial ones, rivalries for status, fluctuations in the balance between groups, exploitation of internal rivalries by superiors, and other phenomena that emerged in the 
study of the court society. But as the main regulation of human relationships in large organizations is formalized in a highly impersonal manner, such phenomena usually have a more or less unofficial and informal character today. In court society, we therefore find quite openly and on a large scale many phenomena that exist below the surface of highly bureaucratized organizations" (Elias 1969, 140).

\subsection{A recent example: Manuel Castells' trilogy on the network society}

In the last decades, one of the most influential attempt to understand a societal transition can be found in Manuel Castells' trilogy on the network society, in which he has analyzed the transition from the industrial to the informational era (Castells 2000a, 2000b, 2004a). This transition originated in the late 1960s and mid-1970s, from the alignment of three main "independent processes": a) the information technology revolution, which redefined the foundations of the material culture of industrial modern societies in every sector of the economic and social life; b) the economic crisis of capitalism and statism, with their subsequent restructuring towards new forms and logics; and c) the blooming of cultural social movements, such as libertarianism, human rights, feminism and environmentalism, with the rise of new social identities, values and structures. As Castells has argued:

"The interaction between these processes, and the reaction they triggered, brought into being a new dominant social structure, the network society; a new economy, the informational/global economy; a new culture, the culture of the real virtuality. The logic embedded in this economy, this society, and this culture underlies social action and institutions throughout an interdependent world" (Castells 2000b, 367).

The societal change toward the network society has the shape of a Gould-like punctuated equilibrium evolutionary process. The explicit theoretical hypothesis is that "all major trends of change constituting our new, confusing world are related" (Castells 2000a, 4). The technological revolution of informational economy and society can be seen in the rise of new patterns and a new modus operandi at the levels of business, market and production organization, and a new division of the social labor based on knowledge (Castells 2000a, 2004b). This revolution has exerted a strong influence on the crisis of traditional social order, the end of the patriarchalism, the de-gendering of social institutions, the emergence of new social identities, and a new approach to sexuality and personality. At the same time, the strength of these societal changes has been bolstered by the rise of socio-cultural movements that are oriented to the transformation of the societal values.

Castells has claimed three distinct mechanisms of identity construction: the legitimizing identity, introduced by the dominant institutions to build a civil society in which integrating people and rationalizing "the sources of structural domination"; resistance identity, in which stigmatized and oppressed individuals create solidarity to counter the dominant institutions, often leveraging on communal identities and fundamentalism to affirm the strength of "principles different from or opposed to", like in the case of communitarian movements; and project identity, which involves the 
rise of new social actors and their commitment to constructive programs of societal transformations, like in the famous case of feminism in Western societies (Castells 2004a, 8-9).

The evolution of the network society has been marked by tensions and conflicts, embedded in the aforesaid identity mechanisms. A vivid example is the diffusion of the "resistance identity" in local communities. Under the challenge of the globalized network society, which came to shrink and disarticulate civil society, the typical response at the local level, in most of places invested by this process of change, was the strengthening of the "communal resistance" as a source of meaning and social identity, with the personal identity becoming a "prolongation" of the communitarian values (Castells 2004a, 11). In this line, Castells has described the resurgence of nationalistic fundamentalism, with nuances from the recent history of Islam, America, Russia and Catalonia.

Following the footsteps of his early famous study on urban movements (Castells 1983), Castells has focused on social and urban movements as bearers of societal change and also symptoms of societal contradictions and conflicts in the globalized world. Castells called them "cultural social movements" because they basically point at the transformation of the societal values (Castells 2004b, 19). By emphasizing on the value of personal freedom, creativity, and individualism, like in the case of feminism and sexuality movements, as well as in most of social movements that originated in the universities of Europe and America between the late 1960s and the mid-1970s, these factors strongly influenced the minds of innovators who have designed the technology revolution, according to a plexus of intersectoral influences that is at the core of the network society (Castells 2004b, 20-22; see also the recent case-study on hackers in Himanen 2001).

Finally, Castells has also emphasized the "black holes" of the network society and of its new global order (Castells 2000b). Looking at a set of empirical data, he has reconstructed: the case of Sub-Saharan Africa, the history of the dualism of America, with the inner-city ghettos-systems of social discrimination and exclusion, and the drama of the abused, over-exploited, underprivileged children all over the world. The common evidence is that social exclusion, poverty, misery and inequality significantly has grown with the growth of the network society, although these processes eventually can involve different social groups and different nations as regard to the past, during a historical process promoting some while excluding the others.

In summary, Castells' account addresses the process of societal transition towards the network society by embracing most of the basic features of the transition processes. We will discuss most of these issues in the next section. These basic features do not entail the relevance of the institutional and cultural diversity, and many of the different empirical trajectories toward the network society, adopted by countries and regions all over the world, under the local pressure of contingent factors, as portrayed in Castells (2004b); (see also the comparison between Silicon Valley and Finland in Himanen and Castells 2004).

Like in the case of Norbert Elias' court society, Castells' trilogy also elucidates the conflicting natures of societal transitions and emphasizes what Wilenius has called the "significance of human experience as a fundamental unit of social change" (Wilenius 1998). The main finding is that the understanding of a far-reaching synthetic societal processes, like transitions, rests on the understanding of those profound changes 
that have appeared at the levels of individuals, human reasoning and experiences, as though they were footprints of the overall transition. As Wilenius has rightly noted:

"It is only this realization [the reference to the human experience] which enables us to understand Castells' drive to link the emergence and consolidation of the new social movements to such diverse phenomena as the revolution of information technology, the collapse of communism, the de-sanctification of the patriarchal order, the emergence of an informational/global economy and the networking form or organization. What unites all these phenomena is human experience, and it is only through the reflective character of the human mind that these processes and events gain their momentum and significance" (Wilenius 1998, 274).

\section{Discussion}

Elias and Castells' accounts on transitions show some clear limits that have reference to a recognized practice in social sciences. As a matter of fact, most of social scientists who deal with societal changes are inclined to produce big picture accounts, with widely spanned descriptions, historical depths and suggestive intuitions, while ignoring the advantage of formalizing models to find generative explanations. Most of the available accounts of societal transitions in social sciences are based on umpteen variety of materials, in-depth analyses, and qualitative and 'un-formalized' models of analysis. A clear consequence is that it is very difficult and expensive to derive testable and/or generalized theories from these accounts.

It is worth noting that this same issue can be addressed also to the recent literature on socio-technological transitions, which is the first reference of the recent transition field (e.g., Geels 2002, 2004). Too much factors, variables and phenomena are taken into account at the same time, with the consequence that the analysis is powerful at a descriptive level but low at an analytical level. Moreover, each branch of the literature on transitions seems to be inclined towards producing its own labels, concepts and models, with the consequence that generalization and theoretical cumulativeness, which are the core elements of the scientific progress, are difficult to achieve (e.g., see the recent dispute in Hommels et al. 2007).

On the contrary, the few social scientists who have elaborated sound theoretical models, such as Granovetter and his well known threshold model of collective behavior (Granovetter 1978; Granovetter and Soong 1988), and, more recently, Novak and Vallacher (2001), who have created a simulation model to understand the relevance of social influence in the diffusion of societal changes, have focused just on particular and restricted aspects of societal transitions. After all, an attempt to understand a "societal transition", in the sense we discuss in this paper, was not the original purposes of these studies. The consequence is that concepts and theories expressed in these studies can help identify potential mechanisms of the transition processes, such as tipping points and micro-macro threshold phenomena, but can not result in a coherent theory on transitions.

How can we conciliate an analytical approach to societal phenomena based on formalized models, attention to generative explanations, and theoretical simplification 
and reduction with the rich descriptive and socio-historical accounts summarized in Sect. 3?

Let me first focus on some foundational statements that can be draw from Elias and Castells' accounts, and in general, from standard social science approaches to transitions. Following Elias and Castells' accounts illustrated in Sect. 3, we can suggest these foundational statements:

a) A societal transition is a large-scale and long-term macro process through which a given social system comes to radically change its structural basis, in terms of new socio-technical practices, governance rules, social and economic institutions, cultural frames, and patterns of social life.

b) A social transition is the outcome of the alignment of underlying processes of change that occur in different sectors (i.e., technology, social life and relationships, politics, personality) and that are traceable at different levels of analysis (micro, "meso" and macro).

c) A societal transition is the offshoot of many hidden and/or manifested conflicts and tensions among social groups around the definition of the reality and of societal goals, in an out-of-equilibrium system where the strength of the established institutions become to disappear and new social institutions emerge that are characterized by a certain degree of systemic coherence.

As a consequence, what societal transition scientists are called to explain seems to be a twofold phenomenon, that is, the emergence of micro-macro systemic change and the alignment of changes occurring in different sectors of social life. All the definitions given Elias and Castells' accounts of particular transitions seem to be more focused on the second side of the coin. These studies were aimed to explain how changes in different sectors of the social systems aligned themselves to give rise to a societal transition in a long time period. For example, Castells described the alignment between technological, political and cultural changes in contemporary societies, trying to bring these changes back to the growth of individualism and libertarianism in many sectors of the social systems in a progressively networked society. While describing the emergence of the court society, Elias identified the growth of the interdependence of social groups within the court (i.e., the so-called "courtization") combined with the centralization of political and administrative power as the explanatory mechanism that accounts for the rise and fall of the court society. But, in both cases, what seems to lack is a sound identification of the micro-macro generative mechanisms of transitions with a clear traceability of causal links of changes across sectors of social systems that can allow us to map the translation from micro causes to macro consequences. As a matter of fact, it is easy to recognize in these two excellent pieces of standard social science an analytic gap between the detailed description of empirically grounded phenomena (i.e., the changing patterns of urban life in contemporary Western societies or the reengineering of business organizational models driven by new information technology applications, in Castells' case; the ceremony of the King's lever or the change in households' structures, in Elias' one) and the emergence of a transition at a macro level. In summary, these standard examples are full of interesting indications on transitions, as well as of descriptive details, but leave on the ground a big question: How is it possible to map the translation between micro 
caused and macro consequences, as well as between sectoral phenomena and global patterns, in societal transitions?

According to the well known Coleman framework (Coleman 1990), the explanation of the emergence of societal transition patterns would require to grasp the complex translation between macro ex-ante social situation (i.e., established institutions and structural constraints), micro behavior and interaction of agents (i.e., new beliefs and innovative practices) and consequences at a macro level (i.e., the emergence of new institutions and structural modifications). Following the literature on social simulation (e.g., Conte et al. 2001; Macy 2002; Squazzoni 2008), what should be explained in transition studies is how a transition pattern emerges from agents' interaction, how this local pattern spreads across different sectors, becoming a macro global pattern, and how this process reinforces the change at a micro level. Taking into account this micro-macro-micro link means paying attention to the feedback between micro and macro levels of analysis.

On this problem there is a vast literature that has explored the so called "micromacro link" in complex social systems, while dealing with the crucial and disputed idea of "social emergence" (e.g., Gilbert 1996; Sawyer 2005; De Haan 2006; Squazzoni 2008). According to this literature, it is possible to identify certain types of emergent properties that characterize the societal systems that are called "first order" and "second-order" emergent properties. A first-order emergent property is a macro level property, i.e., a macro pattern, behavior, structure or dynamic, that is generated through decentralized and localized interaction among agents in terms of unintended and unplanned micro-macro consequences. A pattern is called of "secondorder" when it is cognitively recognized by agents that have yielded it and if, as a consequence, it can be intentionally supported, maintained, changed or contrasted by the same agents that yielded it. According to this second type of property, the pattern generated at a macro level by agents' interaction feeds back directly onto the micro level.

It is reasonable to suppose that most of social patterns, such as transitions, call for both these properties. This is because social systems are characterized by the presence of cognitive reflexive agents capable of recognizing the macro features of the system in which they are embedded, as well as the macro consequence of their actions. If this is true, transition models should take into account these micro-macro-micro levels' feedbacks.

To support this idea, it is worth summarizing two well known evidences in social simulation literature (e.g., Squazzoni 2008). Firstly, it is commonly recognized that, when social agents interact under social influence dynamics, driven by observing others' behavior and in particular the behavior of the majority of a group or a population, significant micro-macro changes able to reverse previous standard behavior of the social system are expected to occur. This happens because of the well known micro-macro mechanisms called bandwagon, tipping point and domino effect. These mechanisms reinforce the diffusion and the convergence of a societal system on some macro outcomes that are difficult to predict looking only to the behavior of single agents (e.g., Casti 1994; Ball 2004). This is the power of interaction on the micro-macro aggregation (Squazzoni 2008). Secondly, there is evidence that social agents are capable of building societal artifacts, such as rules and institutions, that help the regulation of social systems by strengthening the macro-micro 
feedback, i.e. by promoting and maintaining formal norms and sanctions that reduce the variety and heterogeneity of behavior at the micro level (e.g., Conte et al. 2001; Boero et al. 2008). This is the power of social order institutions onto agents' behavior.

Sociologically speaking, these should be conceived as twofold forces always at work in societal phenomena. The first force is driven by agents' heterogeneity (i.e., in terms of beliefs, desires and resources) and change (i.e., new ideas put into action) and has a micro-macro emergent nature. The second one brings to social control and monitoring and has a macro-micro nature. The point is that these competing forces should be taken carefully into account when looking at the emergence and the strengthening of transitions. It is expected that, while emergence of macro changes has mainly to do with first types of emergence mechanisms mentioned above, where old patterns and behavioral models are put under question, reconsidered and changed by agents, the strengthening and maintaining of a new institutional order has more to do with the capability of building macro-micro institutional scaffolds and norms that reduce heterogeneity and variety at the micro level.

These are the main aspects that a social scientist would expect to find adequately emphasized in societal transition models.

\section{Concluding remarks: toward an agent-based computational approach to transitions}

In an oversimplified perspective, social scientists can be more or less divided in three groups. The first ones follow narrative methods, believe that human and social affairs are too much complicated to be grasped with formalized models, believe that everything changes, there is no law, and that the scope of scientists should be to investigate all the turns of the reality and to explain the specificity. Usually, their studies are published in long papers and voluminous books, with no recourse to any formalism. The second ones follow sound methods to process aggregate data on social variables and factors, believe that observed relationships among macro factors can allow explain how things work in societies, and suggest that the scope of scientists should be to dissect observable trends in available data. Their studies are full of statistical data with worked out socio-econometric regression methods and techniques but can not support sound micro-macro causal generative explanations. Finally, social scientists of the third group believe that in principle there is no difference between social and physical sciences, that the same methods can be applied to both, that complicated factors can be reduced to simple explanations, that, as for physical sciences, the social complexity lies hidden in macro patterns emerging from interaction among agents. They firmly believe that formalization and modeling can help in doing a better science, that is, a science that is able to produce explanations of empirical phenomena and well informed theoretical generalizations. In recent years, after many decades in a box, the room for these social scientists of the third type, which represent the standard type in any kind of science, is making larger also in the social sciences.

Until now, social scientists who aimed at studying societal transitions have followed the first type of belief, as Elias and Castells did too. The common view was that transitions are complicated social processes that require complicated explanations. 
Qualitative and detailed accounts have ruled over the other approaches and methods. On the other hand, recently, societal transition researchers have started to apply concepts from complexity sciences, with the purpose to describe macro-dynamics exhibited by a social system over time, in terms of their pre-development, take-off, acceleration and stabilization phase (e.g., Geels 2002; Martens and Rotmans 2005). Unfortunately, until now, these praiseworthy applications have been more metaphorical than concrete.

Moreover, it is worth noting that the few present societal transition models seem more attracted towards the description of multi-level system models and to system dynamics in a complex way, than in understanding the micro-macro generative mechanisms of transitions from simple principles (e.g., Geels 2002; Martens and Rotmans 2005). Unlike social scientists, such as Elias and Castells, most of the present transition analyses do not satisfy the first principle of any possible generative explanation of social phenomena: the need for agent-based foundations, that is, the explicit reference to agents, behavior and interactions among social agents.

In this direction, an agent-based computational approach to transitions is needed that allow us to focus on mechanisms that lie behind the diachronic nature of these phenomena. Agent-based models allow us to bring into focus the transition mechanisms mentioned above:

i) an ex-ante macro societal structure, with given institutional and structural constraints

ii) heterogeneous agents (i.e., in terms of beliefs, goals, resources, position in the social structure)

ii) an interaction structure

iv) an environment

v) the emergence of patterns over time

vi) the diachronic influence of macro patterns on micro behaviour (e.g., Axelrod 1997; Macy and Willer 2002; Epstein 2006; Gilbert 2008).

Moreover, agent-based models allow us to obtain an ontological correspondence between modeled agents and real-world actors, avoiding the limits of mathematical and standard simulation methods in dealing with agent's heterogeneity. They allow us to give an explicit representation of the environment (i.e., geographical, physical, social), in which agents are embedded, and to introduce different interaction structures so to understand how these structures can impact on the micro-macro dynamics. Finally, they allow us to simulate and analyze emerging macro patterns as well as macro-micro influences (Gilbert 2008). Because of these peculiarities, they seem particularly suitable for modeling societal phenomena and exploring generative mechanisms-based explanations (Hedström 2005; Epstein 2006), without giving up too much realism (Troitzsch 1997). The diachronic nature of societal transitions that was vividly sketched in Elias and Castells' accounts could be carefully analyzed and their mechanisms clearly dissected through agent-based models.

In conclusion, this paper has suggested some humble guidelines toward an analytical approach to societal transitions that should be, on one hand, strongly attached to social science evidence, background and experience, and, on the other hand, capable of genuinely benefiting from formal modeling and computational techniques. The 
ideal solution for transition studies would be to strengthen formalization, modeling, theoretical parsimony and generalization, thereby avoiding the risk of formulating the societal transition models on weak social science theories. If this is true, the consequence is that future developments in the study of societal transitions will heavily depend on the establishment of effective and intense collaborations between social scientists, experts in societal transitions, and computational social scientists.

Acknowledgements The arguments of this paper have been substantially influenced by the climate and the ideas that took hold during the workshop on "Computational and Mathematical Approaches to Societal Transitions" that was held in Leiden, February-March 2007. My grateful acknowledgements to all the participants, in particular to Jans de Haan, Harry Te Riele, Michel Schilperhood, Peter Davis, Riccardo Boero and to the so-called "Boat People". Finally, I would like to thank Jos Timmermans and two anonymous referees for some very helpful remarks on a preliminary version of this paper. The usual disclaimer applies.

\section{References}

Aassve A, Billari FC, Spéder Z (2006) Societal transition, policy changes and family formation: evidence from Hungary. Eur J Popul 22(2):127-152

Anderson P (1974) Lineages of the absolutist state. Verso, London

Axelrod R (1997) The complexity of cooperation: agent-based models of competition and collaboration. Princeton University Press, Princeton

Ball P (2004) Critical mass. How one thing leads to another. Arrow Books, London

Black CE (1966) The dynamics of modernization. Harper, New York

Boero R, Castellani M, Squazzoni F (2008) Individual behavior and macro social properties. An agentbased model. Comput Math Organ Theory 14:156-174

Boudon R (1992) Action. In: Traité de sociologie. Presses Universitaires de France, Paris, pp 21-55

Boudon R (1999) Les sens des valeurs. Presses Universitaires de France, Paris

Braudel F (1979) Civilization and capitalism, 15th-18th century, III vols. University of California Press, Berkeley, Reprint edition 1992

Byrne D (1998) Complexity theory and the social sciences. An introduction. Routledge, London

Castellani F, Quitterer J (eds) (2007) Agency and causation in the human sciences. Mentis, Paderborn

Castells M (1983) The city and the grassroots. University of California Press, Berkeley and Los Angeles

Castells M (2000a) The information age. Economy, society and culture, Volume I-the rise of the network society, 2nd edn. Blackwell, London

Castells M (2000b) The information age. Economy, society and culture, Volume III—end of millennium. Blackwell, London

Castells M (2004a) The information age. Economy, society and culture, Volume II-the power of identity, 2nd edn. Blackwell, London

Castells M (2004b) Informationalism, networks, and the network society: a theoretical blueprint. In: The network society. A cross-cultural perspective. Edward Elgar, Cheltenham, pp 3-45

Casti J (1994) Complexification. Explaining a paradoxical world through the science of surprise. Harper Collins Publishers, Hillsdale

Coleman JS (1990) Foundations of social theory. Harvard University Press, Cambridge

Conte R, Edmonds B, Scott M, Sawyer RK (2001) Sociology and social theory in agent-based social simulation: a symposium. Comput Math Organ Theory 7:183-205

Cox OC (1974) The problem of societal transition. Am J Sociol 79(5):1120-1133

De Haan J (2006) How emergence arises. Ecol Complex 3(4):293-301

Durkheim E (1893) The division of labour in society. Free Press, Glencoe, 1964

Eisenstadt SN (1973) Tradition, change and modernity. Prentice-Hall, Englewood Cliffs

Elias N (1939) The civilizing process, 2nd edn. Blackwell, London, 2000

Elias N (1969) The court society. Pantheon, New York, 1983

Epstein JM (2006) Generative social science. Studies in agent-based computational modeling. Princeton University Press, Princeton and Oxford 
Feaver G (1969) From status to contract: a biography of sir Henry Maine 1822-1888. Longmans Green, London

Fisher-Kowalski M, Haberl H (eds) (2007) Socio-ecological transitions and global change. Trajectories of social metabolism and land use. Edward Elgar, Cheltenham

Geels FW (2002) Technological transitions as evolutionary reconfiguration processes: a multi-level perspective and a case-study. Res Policy 31:1257-1274

Geels FW (2004) From sectoral systems of innovation to socio-technical systems. Insights about dynamics and change from sociology and institutional theory. Res Policy 33:897-920

Geels FW, Schot J (2007) Typology of sociotechnical transition pathways. Res Policy 36:399-417

Gilbert N (1996) Holism, individualism and emergent properties. An approach from the perspective of simulation. In: Hegselmann U, Mueller R, Troitzsch KG (eds) Modelling and simulation in the social sciences from the philosophy point of view. Kluwer Academic, Dordrecht, pp 1-27

Gilbert N (2008) Agent-based models. Sage, London

Granovetter M (1978) Threshold models of collective behavior. Am J Sociol 83:1420-1443

Granovetter M, Soong R (1988) Threshold models of diffusion and collective behavior. J Math Sociol 9:165-179

Hedström P (2005) Dissecting the social. On the principles of analytical sociology. Cambridge University Press, Cambridge

Hedström P, Swedberg R (eds) (1998) Social mechanisms. An analytical approach to social theory. Cambridge University Press, Cambridge

Himanen P (2001) The hacker ethic and the spirit of information age. Random House, New York

Himanen P, Castells M (2004) Institutional models of the network society: Silicon Valley and Finland. In: Castells M (ed) The network society. A cross-cultural perspective. Edward Elgar, Cheltenham, pp 49-83

Hommels A, Peters P, Bijker WE (2007) Reply to Geels and Schot. Res Policy 36:1102-1103

Loyal S (2004) Elias on class and stratification. In: Loyal S, Quilley S (eds) The sociology of Norbert Elias. Cambridge University Press, Cambridge, pp 122-141

Loyal S, Quilley S (2004) Towards a 'Central Theory': the scope and the relevance of the sociology of Norbert Elias. In: Loyal S, Quilley S (eds) The sociology of Norbert Elias. Cambridge University Press, Cambridge, pp 1-22

Macy M (2002) Social simulation. In: Smelser NJ, Baltes P (eds) International encyclopaedia of the social and behavioral science. Oxford University Press, Oxford

Macy M, Willer R (2002) From factors to actors: computational sociology and agent-based modelling. Am Sociol Rev 28:143-166

Martens P, Rotmans J (2005) Transitions in a globalising world. Futures 37:1133-1144

Novak A, Vallacher RR (2001) Societal transition: toward a dynamical model of social change. In: Wosinska W et al (eds) The practice of social influence in multiple cultures. Lawrence Erlbaum, Mahwah, London, pp 151-171

Parsons T (1966) Societies: evolutionary and comparative perspectives. Prentice-Hall, Englewood Cliffs

Parsons T (1971) The system of modern societies. Prentice-Hall, Englewood Cliffs

Parsons T, Shils E (1951) Toward a general theory of action. Harvard University Press, Cambridge

Raskin P et al (2002) Great transformation. The promise and lure of the times ahead. A report of the global group scenario. Stockholm Environment Institute, Boston

Rosenberg N, Birdzell LE (1987) How the west get rich: the economic transformation of the industrial world. Basic Books, New York

Rotmans J, Kemp R (2003) Managing societal transitions: dilemmas and uncertainties: the Dutch energy case-study. OECD report. www.oecd.org/dataoecd/6/31/2483769.pdf

Rotmans J, Kemp R, Van Asselt M (2001) More evolution than revolution: transition management in public policy. Foresight 3:17

Sawyer RK (2005) Social emergence. Societies as complex systems. Cambridge University Press, Cambridge

Spawforth AJS (ed) (2007) The court and court society in ancient monarchies. Cambridge University Press, Cambridge

Squazzoni F (2008) The micro-macro link in social simulation. Sociologica 2: http://www.sociologica. mulino.it/journal/article/index/Article/Journal:ARTICLE:179

Szakolczai A (2000) Norbert Elias and Franz Borkenau: interwined life-works. Theory, culture and society. Explor Crit Soc Sci 2:45-71

Tonnies F (1887) Community and society. Michigan State University Press, East Lansing 
Troitzsch KG (1997) Social sciences simulation. Origins, prospects, purposes. In: Conte R et al (eds) Simulating social phenomena. Springer, Berlin, Heidelberg, pp 41-54

Van den Berg J, Kemp R (2008) Transition lessons from economics. In: Van den Bergh J, Bruinsma FR (eds) Managing the transition to renewable energy. Theory and practice from local, regional and macro perspectives. Edward Elgar, Cheltenham, Northampton

Van den Berg J, Bruinsma FR (eds) (2008) Managing the transition to renewable energy. Theory and practice from local, regional and macro perspectives. Edward Elgar, Cheltenham, Northampton

Van Krieken R (1998) Norbert Elias. Routledge, London

Wallerstein I (1974) The modern world-system I. Capitalist agriculture and the origins of the European world-economy in the sixteenth century. Academic Press, New York

Wilenius M (1998) A new globe in the making: Manuel Castells on the information age. Acta Sociol. 41:269-276

Flaminio Squazzoni is Assistant Professor of Economic Sociology (University of Brescia). His main field of research is social simulation. He is Review Editor of JASSS. 